\title{
HIV protease inhibitors block human preadipocyte differentiation, but not via the PPAR $\gamma /$ RXR heterodimer
}

\author{
J M Wentworth ${ }^{1}$, T P Burris ${ }^{2}$ and V K K Chatterjee ${ }^{1}$ \\ ${ }^{1}$ Level 5, Department of Medicine, Addenbrookes, Cambridge CB2 2QQ, UK \\ ${ }^{2}$ Department of Pharmacology, University of Medicine and Dentistry of New Jersey, RW Johnson Medical School, Piscataway, New Jersey 08854, USA \\ (Requests for offprints should be addressed to V K K Chatterjee; Email kkc1@mole.bio.cam.ac.uk)
}

\begin{abstract}
A recent prospective clinical study has shown that antiviral therapy with HIV protease inhibitors (PIs) is associated with a syndrome of peripheral fat wasting (lipodystrophy) and disordered glucose and lipid metabolism (Carr et al. 1999). We have studied the effects of indinavir and saquinavir, two HIV protease inhibitors, on cultured primary human preadipocytes and report that these compounds inhibit their differentiation.
\end{abstract}

However, we find that these agents do not inhibit either transcriptional activation or adipocyte $\mathrm{P} 2$ gene induction by the PPAR $\gamma /$ RXR nuclear receptor heterodimer. Together, our findings suggest that impaired adipogenesis is the basis of PIassociated lipodystrophy, but that this occurs via a PPAR $\gamma /$ RXR-independent mechanism.

Journal of Endocrinology (2000) 164, R7-R10

\section{Introduction}

The novel HIV protease inhibitors (PIs) are highly effective antiviral agents for the treatment of HIV infection (Danner et al. 1995, Hammer et al. 1997). However, a syndrome of peripheral fat wasting (lipodystrophy) in association with PI therapy has recently been described (Carr et al. 1998a, Carr et al. 1999). This syndrome is quite common (over 80\%), progressive and associated with hyperlipidaemia and glucose intolerance. These metabolic complications are also seen in other forms of lipodystrophy (Jackson et al. 1997) and in mice with targeted ablation of adipose tissue (Moitra et al. 1998), suggesting that PIs may exert direct toxic effects on adipose tissue in vivo.

Adipocytes are derived from fibroblast-like preadipocyte precursor cells (Tontonoz et al. 1995). A key mediator of preadipocyte differentiation is the peroxisome proliferatoractivated receptor-gamma (PPAR $\gamma$ ) (Tontonoz et al. 1994a), a ligand-dependent transcription factor which is a member of the nuclear receptor superfamily. PPAR $\gamma$ enhances target gene transcription in preadipocytes and other contexts by binding to specific DNA response elements as a heterodimer with retinoid-X-receptor (RXR) (Tontonoz et al. 1994b). It has therefore been hypothesised that the function of the PPAR $\gamma /$ RXR heterodimer is inhibited by protease inhibitors, leading to lipodystrophy (Carr et al. 1998b).

In this study, we have examined the effects of the HIV protease inhibitors indinavir and saquinavir on the differentiation of primary human preadipocytes. We show that these antiviral agents inhibit both basal and ligand (BRL49653, LG100268) -stimulated preadipocyte differentiation, yet do not impair PPAR $\gamma /$ RXR-mediated induction of the adipocyte P2 target gene in preadipocytes or transcriptional activation by the receptor heterodimer. PIs might therefore cause lipodystrophy by inhibiting preadipocyte differentiation in vivo, but via a mechanism independent of the PPAR $\gamma / \mathrm{RXR}$ heterodimer.

\section{Materials and Methods}

Indinavir and saquinavir were supplied by Merck and Roche respectively and dissolved in ethanol. Tissue culture reagents were obtained from Sigma unless otherwise stated. Preadipocytes were isolated from human breast adipose tissue by dissection into $1-2 \mathrm{~mm}^{3}$ pieces and digestion in Hanks Buffered Salts Solution supplemented with $2 \% \mathrm{w} / \mathrm{v}$ bovine serum albumin and $3 \mathrm{mg} / \mathrm{mL}$ type II collagenase. Cells were cultured to confluence in SC medium (DMEM F12 supplemented with $10 \%$ fetal bovine serum (Labtech), $1 \% \mathrm{v} / \mathrm{v}$ penicillin/streptomycin solution (P/S) and $2 \mathrm{mM} \mathrm{L-glutamine).}$ Differentiation was induced using SF medium (DMEM-F12 supplemented with $1 \% \mathrm{v} / \mathrm{v} \mathrm{P} / \mathrm{S}, 2 \mathrm{mM}$ L-glutamine, $33 \mu \mathrm{M}$ biotin, $17 \mu \mathrm{M}$ pantothenic acid, $10 \mu \mathrm{g} / \mathrm{mL}$ human apotransferrin, $0.2 \mathrm{nM} \mathrm{T3}, 100 \mathrm{nM}$ dexamethasone and $500 \mathrm{nM}$ bovine insulin) $\pm 0.1 \mu \mathrm{M}$ BRL49653 or $0.1 \mu \mathrm{M}$ LG100268 (Adams et al. 1997a). Glycerol-3-phosphate dehydrogenase enzyme activity, an established marker of adipogenesis (Tontonoz et al. 1994a), was assessed between 14 to 21 days post induction of differentiation as previously described (Adams et al. 1997a), and normalised to total lysate protein. Transient transfection assays were performed using the calcium phosphate technique in 24-well cultures of 293EBNA cells as 


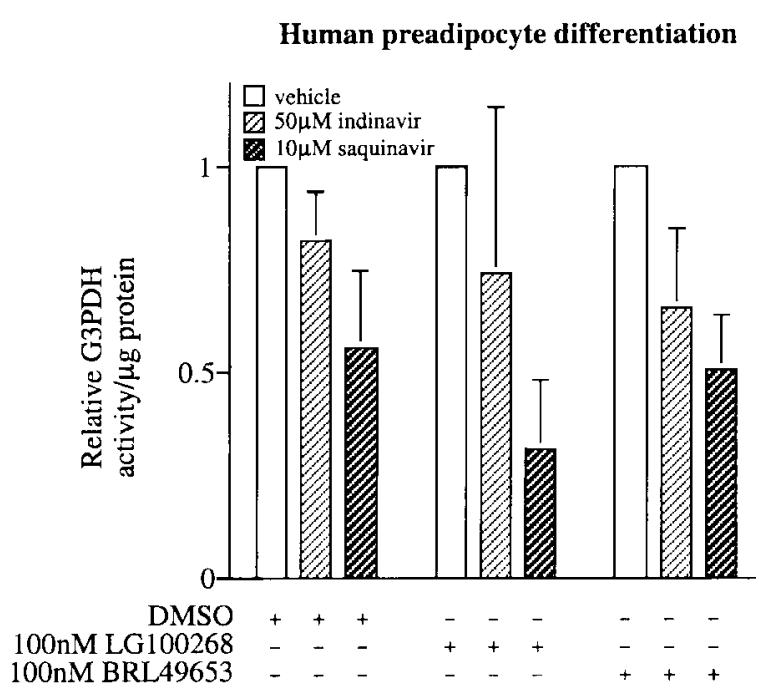

Figure 1 Indinavir and saquinavir inhibit human preadipocyte differentiation. Confluent cells cultured in 6 -well plates were treated with SF medium supplemented with vehicle or protease inhibitor in the presence of PPAR (BRL49653) or RXR (LG100268) -specific ligands as shown. G3PDH enzyme activity, normalised to total protein concentration, is expressed relative to vehicle-treated cells. Enzyme activity was induced 10 fold and 8 fold by BRL49653 and LG100268 respectively, consistent with the known adipogenic activity of these ligands. The results shown represent the mean+S.E.M. of three independent estimations.

previously described (Collingwood et al. 1994). $500 \mathrm{ng}$ PPARETKLUC reporter vector, $100 \mathrm{ng}$ Bos $\beta$-gal internal control vector and $50 \mathrm{ng}$ pcDNA3 or pcDNA3-PPAR $\gamma$ expression vector (Adams et al. 1997b) were added to each well. aP2 mRNA expression was assessed using the Quantigene branched DNA assay (Bayer) according to the protocol previously described (Burris et al. 1999). For this assay, human preadipocytes were cultured in SC medium and exposed to protease inhibitors and BRL49653 or vehicle (DMSO) in duplicate 96-well plates. $24 \mathrm{~h}$ later, aP2 mRNA was quantitated and normalised to levels of GAPDH mRNA a cellular housekeeping gene.

\section{Results}

Protease inhibitors inhibit human preadipocyte differentiation

Primary human preadipocytes were cultured for 21 days in differentiation (SF) medium supplemented with $50 \mu \mathrm{M}$ indinavir or $10 \mu \mathrm{M}$ saquinavir followed by estimation of glycerol-3-phosphate dehydrogenase (G3PDH) enzyme activity-a well validated marker of differentiation (Adams et al. 1997a). Indinavir and Saquinavir treatment resulted in 20\% and $40 \%$ reduction in G3PDH activity respectively (Fig. 1).
Cells were then treated with thiazolidinedione (BRL49653) or rexinoid (LG100268), which are PPAR $\gamma$ - and RXR-specific ligands respectively and known to enhance differentiation. Similar inhibitory effects of indinavir and saquinavir were observed following 14 days culture in SF medium supplemented with either $0.1 \mu \mathrm{M}$ BRL49653 or $0.1 \mu \mathrm{M}$ LG100268 (Fig. 1).

\section{Protease inhibitors do not impair PPAR $\gamma / R X R$ signalling}

The observation that indinavir and saquinavir inhibit preadipocyte differentiation in response to PPAR $\gamma$ - and RXRspecific ligands raised the possibility that PIs might impair PPAR $\gamma / R X R$-dependent transcription. These antiviral agents were tested in transient transfection assays with the human PPAR $\gamma 2$ isoform and a reporter gene construct. Our results (Fig. 2a) indicate that the basal transcriptional activity of transfected PPAR $\gamma 2$ and endogenous RXR is not altered by saquinavir or indinavir. Furthermore, PPAR $\gamma 2 / R X R$ activation by BRL49653 and LG100268 was also unaffected by the presence of HIV protease inhibitors. Similar results were obtained when the human PPAR $\gamma 1$ isoform was tested (data not shown). Finally, we examined the effect of protease inhibitors on adipocyte P2 (aP2) expression - a well recognised PPAR $\gamma /$ RXR target gene (Tontonoz et al. 1994c). Saquinavir and indinavir had no effect on either basal or BRL49653-induced aP2 mRNA levels in human preadipocytes (Fig. 2b).

\section{Discussion}

In this study, we show for the first time that HIV protease inhibitors can inhibit human preadipocyte differentiation (Fig. 1), with saquinavir having a greater inhibitory effect than indinavir. Whilst the rank order of potency of these two agents has not been directly compared in clinical studies, patients treated with a ritonavir/saquinavir combination are more prone to develop lipodystrophy than those treated with indinavir alone (Carr et al. 1998b). Together, these observations suggest that impaired adipogenesis may account for lipodystrophy associated with these antiviral agents in vivo. Given the role of adipose tissue in lipid and glucose metabolism (Tontonoz et al. 1995), it is possible that the hyperlipidaemia and glucose intolerance observed in PI-associated lipodystrophy are secondary to such impaired adipogenesis.

We find no evidence to support the hypothesis that this effect is mediated by a direct action of PIs on the PPAR $\gamma / \mathrm{RXR}$ heterodimer, as neither indinavir nor saquinavir inhibited PPARETKLUC reporter gene activation in transient transfection assays or aP2 mRNA induction in human preadipocytes (Fig. 2). These findings suggest that the antiadipogenic activity of protease inhibitors we have observed may result from perturbation of additional signalling pathways involved in preadipocyte differentiation. Moreover, the lack of effect of these compounds on PPAR $\gamma / \mathrm{RXR}$ action predicts that the insulin-sensitising thiazolidinediones (the 'glitazones') 


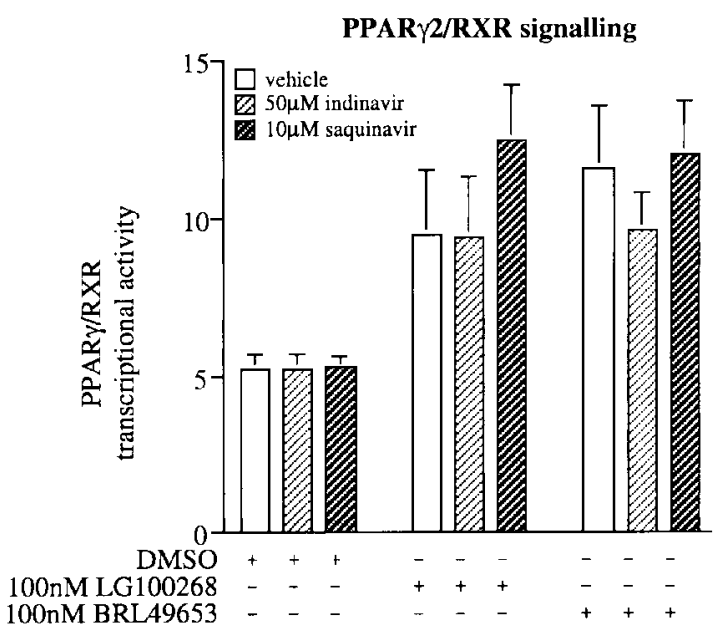

b.

\section{Adipocyte P2 gene expression}

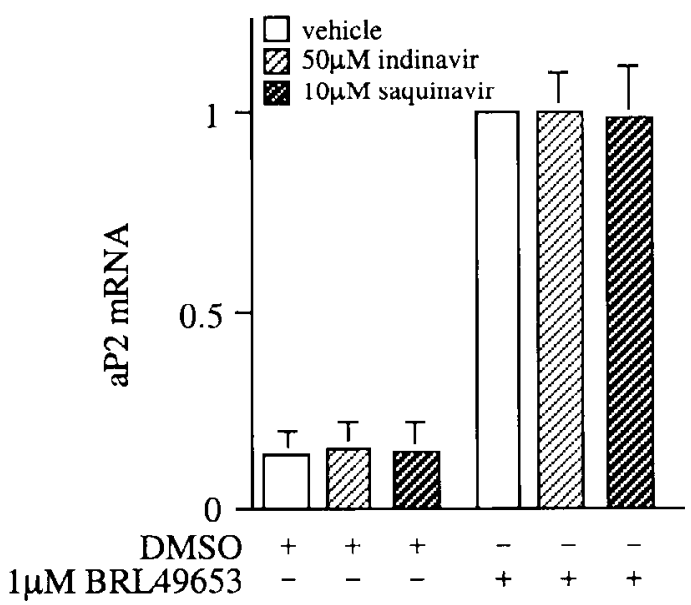

Figure 2 HIV protease inhibitors do not impair the activity of the PPAR $\gamma /$ RXR heterodimer. a. 293EBNA cells were cotransfected with $500 \mathrm{ng}$ PPARETKLUC reporter vector, $100 \mathrm{ng}$ Bos $\beta$-gal internal control vector and $50 \mathrm{ng}$ pcDNA3PPAR 2 expression vector per well and cultured in the presence of protease inhibitors and ligands as shown. Transcriptional activity is expressed relative to cells transfected with empty mammalian expression vector (pcDNA3) and the PPARETKLUC and Bos $\beta$-gal reporter constructs. b. Primary human preadipocytes were grown to confluence in 96-well plates and treated with SF medium supplemented with vehicle or protease inhibitor in the presence of DMSO or BRL49653 as shown. aP2 mRNA levels, normalised to GAPDH mRNA, are expressed relative to those in thiazolidinedione (BRL49653) -treated cells cultured in the absence of protease inhibitor.

may even be effective in the treatment of HIV protease inhibitor-associated diabetes.

\section{Acknowledgements}

JW is supported by an Elmore Scholarship and the Francis and Augustus Newman Foundation and VKKC is funded by the Wellcome Trust.

\section{References}

Adams M, Montague CT, Prins JB, Holder JC, Smith SA, Sanders L, Digby JE, Sewter CP, Lazar MA, Chatterjee VK \& O'Rahilly S $1997 a$ Activators of peroxisome proliferator-activated receptor gamma have depot-specific effects on human preadipocyte differentiation. Journal of Clinical Investigation 100 3149-3153.

Adams M, Reginato MJ, Shao D, Lazar MA \& Chatterjee VK $1997 b$ Transcriptional activation by peroxisome proliferator-activated receptor gamma is inhibited by phosphorylation at a consensus mitogen-activated protein kinase site. Journal of Biological Chemistry 272 5128-5132.

Burris TP, Pelton PD, Zhou L, Osborne MC, Cryan E \& Demarest KT 1999 A novel method for analysis of nuclear receptor function at natural promoters: peroxisome proliferator-activated receptor gamma agonist actions on aP2 gene expression detected using branched DNA messenger RNA quantitation. Molecular Endocrinology 13 410-417.

Carr A, Samaras K, Burton S, Law M, Freund J, Chisholm DJ \& Cooper DA 1998a A syndrome of peripheral lipodystrophy, hyperlipidaemia and insulin resistance in patients receiving HIV protease inhibitors. Aids 12 F51-F58.

Carr A, Samaras K, Chisholm DJ \& Cooper DA $1998 b$ Pathogenesis of HIV-1-protease inhibitor-associated peripheral lipodystrophy, hyperlipidaemia, and insulin resistance. Lancet 351 1881-1883.

Carr A, Samaras K, Thorisdottir A, Kaufmann GR, Chisholm DJ \& Cooper DA 1999 Diagnosis, prediction, and natural course of HIV-1 protease-inhibitor-associated lipodystrophy, hyperlipidaemia, and diabetes mellitus: a cohort study. Lancet $\mathbf{3 5 3}$ 2093-2099.

Collingwood TN, Adams M, Tone Y \& Chatterjee VK 1994 Spectrum of transcriptional, dimerization, and dominant negative properties of twenty different mutant thyroid hormone beta-receptors in thyroid hormone resistance syndrome. Molecular Endocrinology 8 1262-1277.

Danner SA, Carr A, Leonard JM, Lehman LM, Gudiol F, Gonzales J, Raventos A, Rubio R, Bouza E, Pintado V et al. 1995 A short-term study of the safety, pharmacokinetics, and efficacy of ritonavir, an inhibitor of HIV-1 protease. European-Australian Collaborative Ritonavir Study Group. New England Journal of Medicine 333 1528-1533.

Hammer SM, Squires KE, Hughes MD, Grimes JM, Demeter LM, Currier JS, Eron JJ Jr, Feinberg JE, Balfour HH Jr, Deyton LR, 
Chodakewitz JA \& Fischl MA 1997 A controlled trial of two nucleoside analogues plus indinavir in persons with human immunodeficiency virus infection and CD4 cell counts of 200 per cubic millimeter or less. AIDS Clinical Trials Group 320 Study Team [see comments]. New England Journal of Medicine 337 725-733.

Jackson SN, Howlett TA, McNally PG, O'Rahilly S \& Trembath RC 1997 Dunnigan-Kobberling syndrome: an autosomal dominant form of partial lipodystrophy. Qjm 90 27-36.

Moitra J, Mason MM, Olive M, Krylov D, Gavrilova O, MarcusSamuels B, Feigenbaum L, Lee E, Aoyama T, Eckhaus M, Reitman ML \& Vinson C 1998 Life without white fat: a transgenic mouse. Genes and Development 12 3168-3181.
Tontonoz P, Hu E \& Spiegelman BM 1994a Stimulation of adipogenesis in fibroblasts by PPAR gamma 2, a lipid-activated transcription factor. Cell 79 1147-1156.

Tontonoz P, Graves RA, Budavari AI, Erdjument-Bromage H, Lui M, Hu E, Tempst P \& Spiegelman BM 1994b Adipocyte-specific transcription factor ARF6 is a heterodimeric complex of two nuclear hormone receptors, PPAR gamma and RXR alpha. Nucleic Acids Research 22 5628-5634.

Tontonoz P, Hu E, Graves RA, Budavari AI \& Spiegelman BM 1994c mPPAR gamma 2: tissue-specific regulator of an adipocyte enhancer. Genes and Development 8 1224-1234.

Tontonoz P, Hu E \& Spiegelman BM 1995 Regulation of adipocyte gene expression and differentiation by peroxisome proliferator activated receptor gamma. Current Opinion in Genetics and Development 5 571-576. 